\title{
Design of Borneo Virtual Tour Website as a Media for Promotion of Dayak Cultural Tourism Objects, Pampang Village Samarinda
}

\author{
Samosir Fanriston Riko Roradi ${ }^{*}$, Intan Rizky Mutiaz ${ }^{2}$ \\ ${ }^{1}$ Institut teknologi bandung, Indonesia \\ ${ }^{2}$ Institut teknologi bandung, Indonesia \\ ${ }^{*}$ Corresponding author. Email: Samosirfrr@gmail.com
}

\begin{abstract}
The Pampang Cultural Village is located in the North Samarinda sub-district which is a Dayak Kenyah tribal village originating from the Apokayan Highlands. In order to preserve Dayak culture, the East Kalimantan Provincial Government has made Pampang Cultural Village a leading tourist destination, considering the development of the tourism industry is growing rapidly along with technological developments. and high public interest in traveling. A tourist destination that has a unique and different culture from the area of origin of tourists. Knowing tourist destinations is one of the reasons for tourists to decide to travel. Using virtual tour 360 technology will make it easier for tourists to find tourist destinations. This research aims to design a website Virtual Tour conducted using multimedia application development, the Multimedia Development Life Cycle or MDLC, which consists of six stages: concept(concept),design(design), the collection of material (materialcollecting), manufacturing (assembly), testing (testing), and distribution (distribution). Meanwhile, the testing will be carried out in 5 stages, namely: Functional Testing, Usability Testing, Interface Testing, Compatibility Testing, Performance Testing. This research resulted in an application based on a virtual tour website for the promotion of tourist destinations in the city of Samarinda which contains a guide for tourists to be able to reach tourist sites easily and can learn about the Dayak tribe in the cultural village of Pampang, Samarinda City.
\end{abstract}

Keywords: Virtual Tour, Pampang Cultural Village, Dayak Tribe, MDLC

\section{INTRODUCTION}

Tourism is the whole series of activities related to the movement of people who travel or stop temporarily from their place of residence, to one or several destinations outside their living environment which are driven by several needs without the intention of earning a living (Gunn, Clare A: 2002 ). Tourism is a very important sector because it is a source of foreign exchange for the country and is able to make a significant contribution to the development of the nation. Currently the tourism trend is changing, from what was previously conventional tourism to special interest tourism. In special interest tourism, tourists tend to appreciate the environment, nature, culture and attractions in a special way. One of the special interest tourism that is developing in Indonesia is a culturalbased tourism village.
Several regions in Indonesia have also developed a type of culture-based tourism village tourism, one of which is in the city of Samarinda, East Kalimantan Province. Based on Law Number 32 of 2004 concerning Regional Government, that regions are given the right and authority to regulate and manage their respective regions in accordance with the potential possessed by the regions to be developed, as a consequence of the implementation of regional autonomy. Based on Law Number 10 of 2009 concerning Tourism, tourism development is carried out based on benefits, kinship, fair and equitable, balance, independence, sustainability, participatory, sustainable, democratic, equality, and unity which is realized through the implementation of tourism development plans by taking into account diversity, the uniqueness and distinctiveness of culture and nature, as well as the human need for travel. The regional autonomy law is actually a grantor of the 
broadest authority to regional governments to regulate and manage the interests of the community in accordance with regulations. This encourages people to take advantage of the potential that exists in their area. One of them is developing a tourist attraction. Most Indonesians live in rural areas where human and natural resources are located. When linked by the community as the main actor of development with the main potential in rural areas, the village has a very important role. Because directly or indirectly this will have a positive impact for the community in this village. Based on the Regulation of the Mayor of Samarinda Number 23 of 2008 concerning the Elaboration of Duties, Functions and Work Procedures of the Organizational Structure of the Department of Culture, Tourism and Communication and Information of the City of Samarinda, it is the implementing element of regional autonomy in charge of carrying out regional government affairs based on the principle of autonomy and assistance in the tourism sector.

Promotion is finding out unmet consumer needs and wants, finding out and measuring and calculating market size and profit potential, showing market segments served, and designing and improving the right products/services (Zebua, 2016). Marketing communication media that are so diverse have resulted in major changes in the pattern of using marketing communication media (Raihan, 2014). The development of the field of technology and communication as well as the growth of the economic aspects of a number of countries have not been utilized by the Pampang cultural village government. The development of information technology has an impact on tourism products so that they can be displayed on an internet site so that they can be viewed in a wider scope (Sutanto, 2016). . In addition, the website is considered to be able to unite tourist villages in Samarinda in one container that can make it easier for the public or tourists to access information.

A new technology that has emerged in the world of education is Augmented reality, which functions as an information medium that aims as one of the alternative technology-based learning information media. The existence of this information media is expected to make the delivery of information more interesting and able to make users feel interested in using it, thereby making users aware of the information contained on this website. Through website design based on Virtual Tour Technology.

\section{METHODOLOGY}

The research method used in developing this application virtual tour is the Multimedia Development Life Cycle (MDLC). The MDLC method is a method for developing multimedia applications. The virtual tour application is an application that can be classified as a multimedia application because it uses photos, images, audio and even video as the main material / data. MDLC method has six stages, namely the concept (concept), design(design), data collection (collecting material), manufacturing (assembly), testing (testing) and distribution (distribution).

\subsection{Concept (Concept)}

Concept stage, namely ideas (ideas), synopsis, treatment and determining goals, including identification of the audience (the parties concerned). The application to be built is a website-based software that is built dynamically, so that the user of the application consists of 2 users, namely website visitors (users) and website managers (admin). The purpose of the application is as a tool for visitors to get to know the existing tourist objects, as well as a tourism promotion medium to increase tourist attraction. On the main page of the user's website there is information about applications that have been made in the form of text and images, as well as navigation menus to guide and direct the movement of visitors in the application virtual tour. The image on the virtual tour that will be displayed contains a real view of the tourist area in the form of panoramic photos with a 360-degree viewing angle.

\subsection{Design}

Design is to make a detailed specification of the project architecture, style, and material requirements for the project. The design is carried out to describe system requirements, application workflows, and the expected final results of the applications made.

The application to be built is a-based application website and consists of 2 users, namely the admin as a data manager and a user who is a visitor to the application virtual tour.

\subsection{The collection of materials (Materials Collecting)}

At the stage of collecting materials were collected materials, such as clipart images, animations, and audio, following the manufacture of graphics, photos and others needed for the next stage. The primary data in this study is a 360 -degree panoramic image obtained 
by taking pictures directly to the location of the Pampang Cultural Village in several areas, namely the Pampang Cultural Village entrance gate, parking area / main field, traditional houses (Lamin), and Main Hall, rooms inside the lamin, canteen, and souvenir shop area. At each location point, four photos were taken horizontally, namely front (0 degrees), right (90 degrees), back (180 degrees), and left (270 degrees), as well as vertically, namely above (0 degrees) and down (180 degrees).

\section{Design}

1. Concept

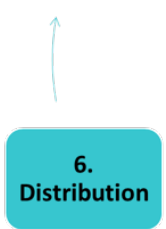

3.Material

Collecting

4. Assembly

5. Testing

Figure 1. MDLC Methodology

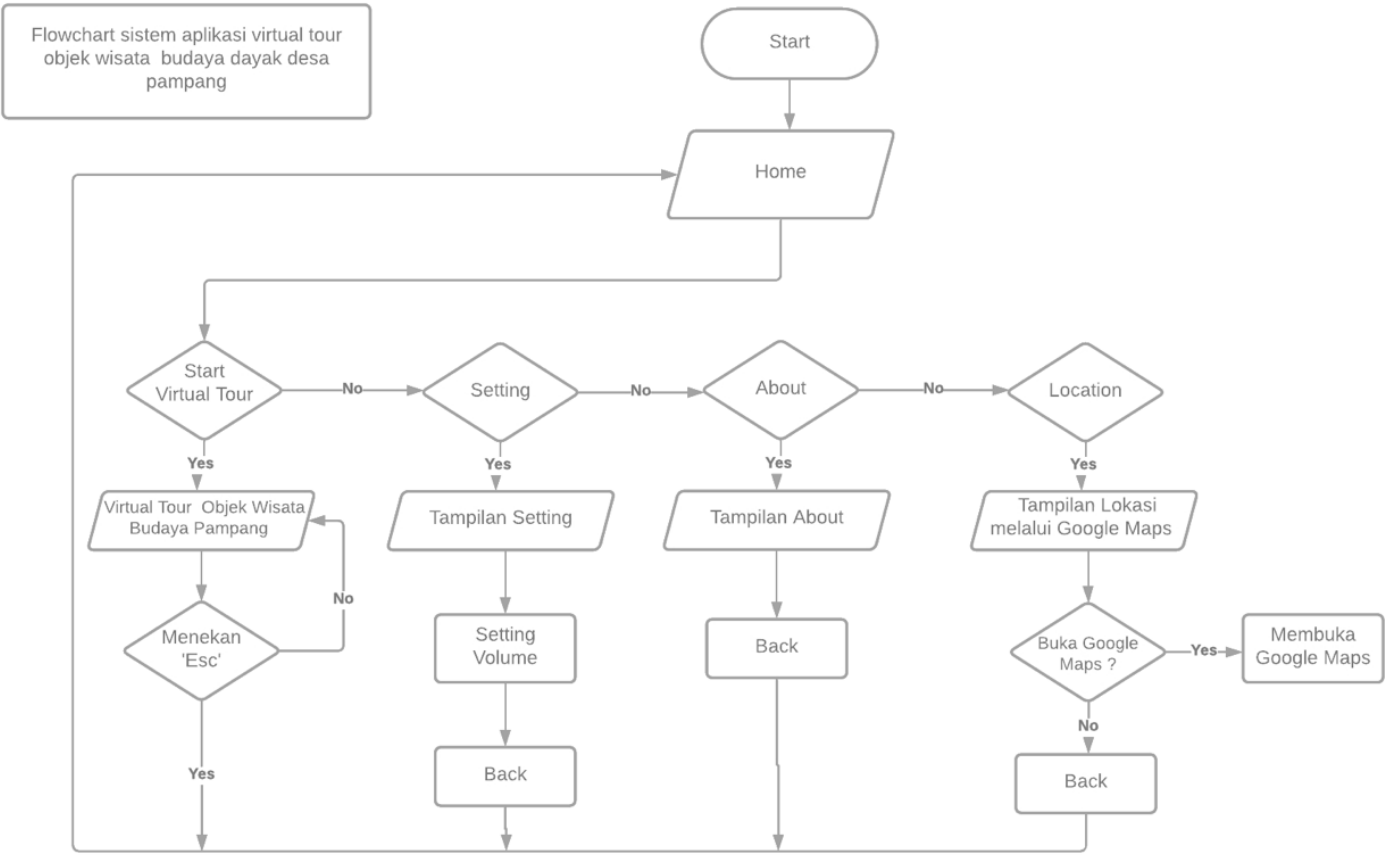

Figure 2. System flowchart

\section{RESULTS AND DISCUSSION}

\subsection{Design (Assembly)}

In the design stage is the stage where all multimedia objects are created. Making applications based on storyboards and navigation 
structures originating from the design stage. The steps in the application creation stage include the process of combining existing images with Panoweaver to create a panorama and Tourweaver making the image application virtual tour, as well as the website coding process. The virtual tour that is displayed contains information in the form of how to use the application, location plans, navigation buttons, and a list of thumbnails of panoramic images. In the virtual tour, there is also a narration in the form of voice to provide descriptions and information about the active panorama. In each panorama there is a button hotspot for users to move from one point to another.
The Interface virtual tour contains several buttons. On the side of the screen there is a navigation button that serves to change the direction of movement of the panoramic image. Hereare the components on the navigation buttons tombol.

\subsection{Testing (Testing)}

Testing phase (testing), carried out after the completion of the manufacture and all data and multimedia components have been incorporated. The function of the test is to ensure that the results of making multimedia applications are as planned. In this research, four stages of testing were carried out, namely Functional Suitability Testing, Performance Efficiency Testing, Portability Testing and Usability Testing.

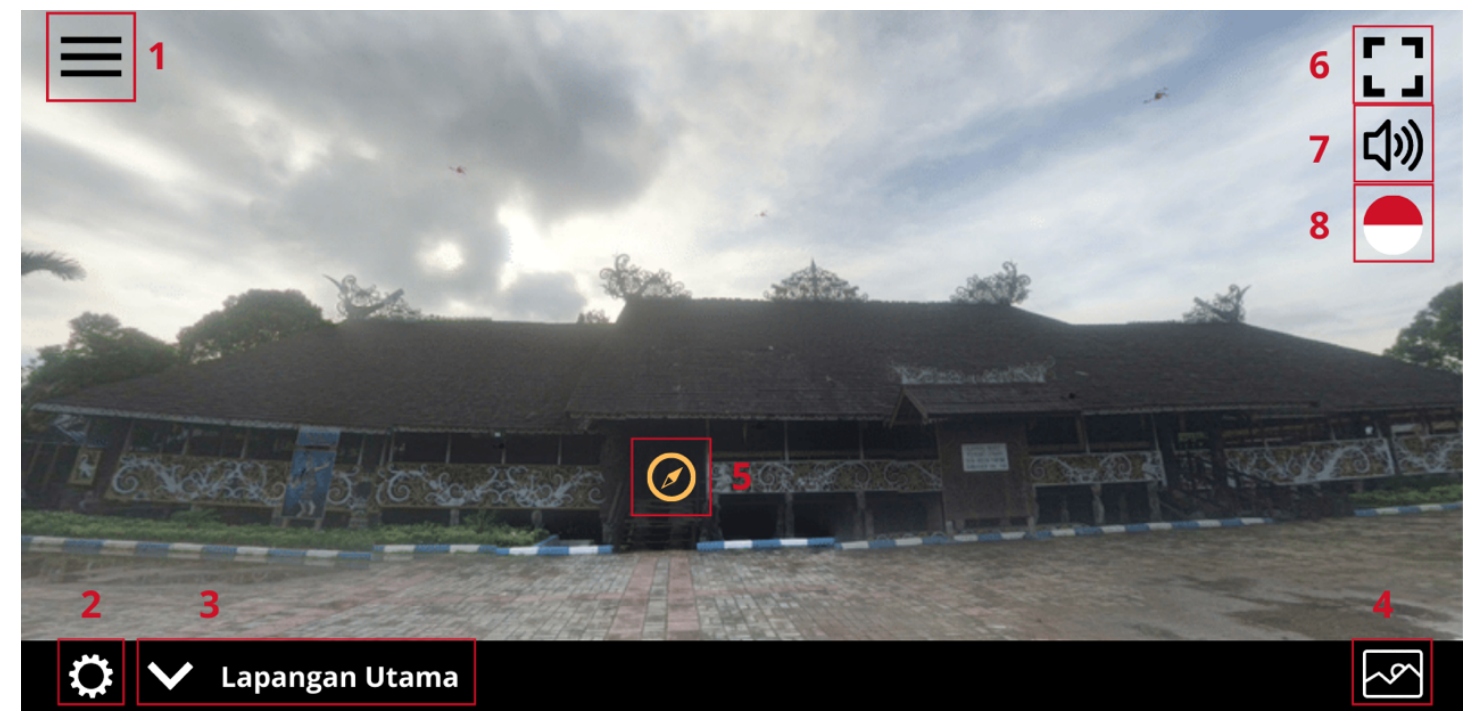

Figure 3

Table 1: Navigation Button

\begin{tabular}{|c|l|}
\hline $\begin{array}{c}\text { Components } \\
\text { Component }\end{array}$ & \multicolumn{1}{c|}{ Function } \\
\hline 1 & Main menu containing About \& Location \\
\hline 2 & Setting menu function \\
\hline 3 & Menu function displaying the current virtual tour view position \\
\hline 4 & Menu function showing all view virtual tour positions \\
\hline 5 & Navigation function leading to the next area \\
\hline 6 & Functions for change to full screen \\
\hline 7 & Menu to activate audio/sound \\
\hline 8 & Menu to change language \\
\hline
\end{tabular}




\section{CONCLUSIONS}

After developing the application virtual tour and conducting testing and viewing the test results data, it can be concluded that the application virtual tour has been successfully developed and is included in the category worthy of being used as a medium of information and tourism promotion in the cultural village of Pampang Samarinda. The "Borneo Virtual" application is designed with the aim that the public can attract tourists to get to know more about the Dayak tribe and visit the Pampanga tourist village in the form of a virtual tour website. Besides being able to find out about Dayak culture through this application, users can also describe the location of tourist destinations so that tourists can prepare themselves when traveling.

The MDLC method requires a fairly long design process with repeated cycles to get the appropriate application design. The Borneo Virtual application has the potential to continue to be developed. The involvement of users to provide criticism and suggestions based on the experience of using the application, it is possible that the shortcomings contained in the application can be improved and improved.

\section{REFERENCES}

[1] Tabrani P. Visual Language. Bandung: ITB Publishing Co.; 1990.

[2] Maddox R, Hogan H. The Definition of Visual Communication Design. Jakarta: Level Publishing; 2007.

[3] Baxter M. Psychology in Design. In: Carter O, Carter J, editors. Education for Visual Communicators. San Francisco: Academic Publishing, 2006; p. 369-380.

[4] Anderson HC. Current status of children's picture book. Paper presented at: IRSCE 2006. Proceedings of the 4th Congress of the International Research Society for Children Education; 2006 Sep 8-10; Queensland, Australia. Berlin: Springfield; 2006. p. 182-191.

[5] Dalton N. Role of design educators. Wimba Journal of Visual Communication Design. 2009; 1(1):8-9.

[6] Mainaky R. Semiotics within Graphic Design. Wimba Journal of Visual Communication Design [serial online]. 2009 [cited 2010 Mar 28];2(2):1823. Available from: http://wimbajournal.org/ 2009/vol2no2.html
[7] Scorsese M, producer; Lonergan K, director. You can count on me [motion picture]. United States: Paramount Pictures 